\title{
What have we known so far for fluorescence staining and quantification of microplastics: A tutorial review
}

\author{
Shengdong Liu ${ }^{1}$, Enxiang Shang $(\bowtie)^{2}$, Jingnan Liu ${ }^{1}$, Yining Wang ${ }^{1}$, Nanthi Bolan ${ }^{3,4,5}$, \\ M.B. Kirkham ${ }^{6}$, Yang Li $\left.(\bowtie)\right)^{1}$ \\ 1 Key Laboratory of Water and Sediment Sciences of Ministry of Education, State Key Laboratory of Water Environment Simulation, \\ School of Environment, Beijing Normal University, Beijing 100875, China \\ 2 College of Science and Technology, Hebei Agricultural University, Huanghua 061100, China \\ 3 School of Agriculture and Environment, The University of Western Australia, Perth, WA 6001, Australia \\ 4 The UWA Institute of Agriculture, The University of Western Australia, Perth, WA 6001, Australia \\ 5 Global Innovative Centre for Advanced Nanomaterials, College of Engineering, Science and Environment, \\ University of Newcastle, Callaghan, NSW 2308, Australia \\ 6 Department of Agronomy, Throckmorton Plant Sciences Center, Kansas State University, Manhattan, KS 66506, USA
}

\section{H I G H L I G H T S}

- Fluorescence staining provides a fast and easy method to quantify microplastics.

- Factors that influence staining are summarized to obtain an optimum staining effect.

- Natural organic matter can be stained by dye and interfere with quantification.

- Fluorescence staining is applied in both field and laboratory studies.

- Future work involves developing new dyes and automated image-analysis methods.

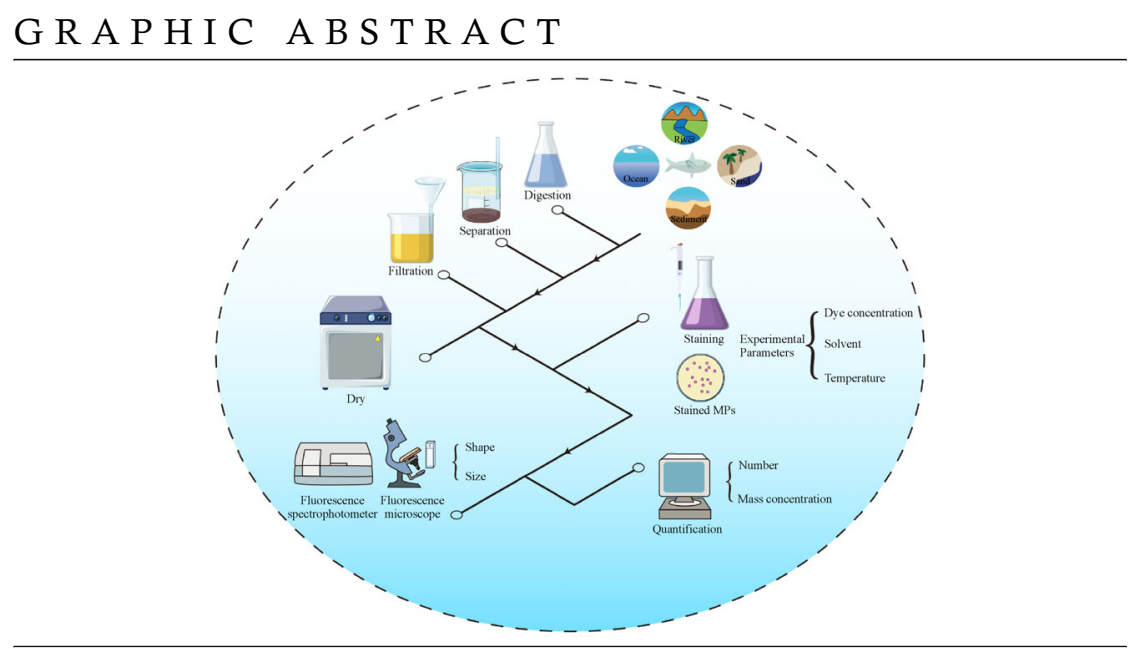

A R T I C LE IN F O

Article history:

Received 23 July 2021

Revised 22 September 2021

Accepted 12 October 2021

Available online 15 November 2021

Keywords:

Plastic particles

Fluorescence dyes

Identification

Concentration quantification

\section{A B S T R A C T}

Understanding the fate and toxicity of microplastics (MPs, $<5 \mathrm{~mm}$ plastic particles) is limited by quantification methods. This paper summarizes the methods in use and presents new ones. First, sampling and pretreatment processes of MPs, including sample collection, digestion, density separation, and quality control are reviewed. Then the promising and convenient staining procedures and quantification methods for MPs using fluorescence dyes are reviewed. The factors that influence the staining of MPs, including their physicochemical properties, are summarized to provide an optimal operation procedure. In general, the digestion step is crucial to eliminate natural organic matter (NOM) to avoid interference in quantification. Chloroform was reported to be the most appropriate solvent, and $10-20 \mu \mathrm{g} / \mathrm{mL}$ are recommended as optimal dye concentrations. In addition, a heating and cooling procedure is recommended to maintain the fluorescence intensity of MPs for two months. After staining, a fluorescence microscope is usually used to characterize the morphology, mass, or number of MPs, but compositional analysis cannot be determined with it. These fluorescence staining methods have been implemented to study MP abundance, transport, and toxicity and have been combined with other chemical characterization techniques, such as Fourier transform infrared spectroscopy and Raman spectroscopy. More studies are needed to focus on the synthesis of novel dyes to avoid NOM's interference. They need to be combined with other spectroscopic techniques to characterize plastic composition and to develop image-analysis methods. The stability of stained MPs needs to be improved.

(C) The Author(s) 2021. This article is published with open access at link.springer.com and journal.hep. com.cn 2021

$\triangle$ Corresponding author

E-mail: shangenx@163.com (E. Shang), liyang_bnu@bnu.edu.cn (Y. Li)

Special Issue-Microplastic and Nanoplastic Pollution: Characterization, Transport, Fate, and Remediation Strategies (Responsible Editors: Wen Zhang, Melissa Pasquinelli \& Yang Li) 


\section{Introduction}

Over the past decades, the production and consumption of plastic products has risen rapidly (Thompson et al., 2004). Due to the continued discharge of plastic products and their low degradation rates, they accumulate in environmental matrixes, including water, sediments, soils, and the atmosphere (Barnes et al., 2009; Liu et al., 2021). Once the plastic products are discharged into the natural environment, large particles may be fractured, weathered, or degraded into microplastics (MPs, $0.1 \mu \mathrm{m}-5 \mathrm{~mm}$ ) and nanoplastics (NPs, $\leqslant 0.1 \mu \mathrm{m})$ via biodegradation and physical and chemical weathering processes (Browne et al., 2011; Cole et al., 2011; Duan et al., 2021). Commercial products, such as personal care products and industrial beads, contain ultrafine plastic particles, which are regarded as the primary source of MPs and NPs (Alimi et al., 2018). The loads of MPs in freshwater, seawater, soil, and sediment are $10^{-5}-10$ items $/ \mathrm{L}, 10^{-6}-10$ items $/ \mathrm{L}$, $1-10^{4}$ items $/ \mathrm{kg}$, and $1-10^{3}$ items $/ \mathrm{kg}$, respectively (McCormick et al., 2014; Shahul Hamid et al., 2018; Zhang and Liu, 2018; Chen et al., 2020; Zhang et al., 2020). Studies have shown that MPs pose a threat to human health and ecosystems, because MPs can be transported via food chains (Carbery et al., 2018; Sun et al., 2019; Liu and Wang, 2020). The increasing load of MPs has drawn the attention of researchers (Wu et al., 2017; Guo et al., 2020; Wang et al., 2021). Thus, studying their abundance is important to assess the impact of MPs on health and to ensure the security of ecosystems.

A fundamental step to understand the distribution, fate, and toxicity of MPs is the identification and quantification of MPs. A variety of approaches have been developed to detect and characterize MPs (Shim et al., 2017; Fu et al., 2020). However, the advantages and limitations of these methods vary. Manual counting of MPs by optical microscopy is one of the most widely used methods to quantify MPs, which has the advantage of convenience but is limited by the operator's subjectivity (Fu et al., 2020). Scanning electron microscopy (SEM), transmission electron microscopy (TEM), and atomic force microscopy (AFM) can provide clear and high-resolution images of MPs, but these methods need to be combined with spectroscopy methods to characterize the chemical composition of MPs (Patchaiyappan et al., 2020). Analysis by Fourier transform infrared spectroscopy (FTIR) and Raman spectroscopy can characterize the specific chemical bonds of MPs, but they are difficult to use to quantify MPs (Fu et al., 2020). Gas chromatography-mass spectrometry (GC-MS) is also an alternative method for measuring the concentrations of monomers or additives in MPs, but it is a destructive method (Shim et al., 2017). All the above methods require expensive instruments, experienced operators, time-consuming pretreatment processes, and complex data analysis, except for the manual counting method via optical microscopy. Therefore, it is necessary to develop a convenient and cheap quantification method for MPs present in the environment.

The fluorescence staining and quantification method provides a fast, convenient, and cheap way to quantify MPs (Maes et al., 2017). This technique uses a dye called Nile Red (NR, 9-diethylamino-5-benzo[ $\alpha]$-phenoxazinone), a lipid soluble fluorescence dye, to stain neutral lipids in biological samples (Greenspan and Fowler, 1985). Afterwards, NR is used to stain synthetic polymers (Jee et al., 2009). Since 2016, the staining ability of MPs by NR has drawn the attention of researchers (Shim et al., 2016; Erni-Cassola et al., 2017; Maes et al., 2017). Maes et al. proposed the identification and quantification method for MPs using NR staining and fluorescence microscopy, and they got an average recovery rate of $96.6 \%$ for marine MPs, which was cross-validated by FTIR (Maes et al., 2017). Recently, heating protocols have been developed to enhance the staining effect, and programmed-imageanalysis software has been applied to quantify fluorescence of MPs automatically (Shim et al., 2016; Erni-Cassola et al., 2017; Karakolis et al., 2019). The MP fluorescence staining and quantification method has achieved a recovery rate of over $90 \%$, which has been validated by FTIR using the same batch of laboratory samples (Shim et al., 2016; Erni-Cassola et al., 2017; Cook et al., 2020; Karakolis et al., 2019). Therefore, the fluorescence staining and quantification method for MPs provides a promising and convenient technique for researchers.

To summarize research on MP characterization and quantification, a literature review of papers published between January 2016 and March 2021 was conducted. A total of 1411 articles were investigated with the following keywords: microplastics, quantification, characterization, detection, sampling, fluorescence, and NR. As shown in Fig. 1, 32\% of the research focused on quantification of MPs, which was more than research in any other area. Currently, most reviews have concentrated on characterization of physicochemical properties, transport, and transformation of MPs, as well as sampling, separation, and digestion procedures of MPs (Hidalgo-Ruz et al., 2012; Fu et al., 2020), but the reviews have ignored the fluorescence-quantification method for MPs.

Thus, we focus on providing a comprehensive overview of the fluorescence staining method to quantify MPs in aquatic environments. The objective of this review is to identify the optimum protocols and best operating conditions for fluorescence staining and quantification of MPs. First, procedures dealing with sample collection, separation, digestion, identification, and quantification are summarized. Next, the advantages and limitations of dye staining and the main factors that influence the dying effect, including the physicochemical properties of MPs and environmental conditions, are summarized. Then, the method itself for the identification and quantification of stained MPs is reviewed. After discussing the application of fluorescence staining and quantification methods for 
MPs being done in current studies, knowledge gaps and future perspective regarding standardized protocols for MP quantification are proposed.

\section{Fluorescence staining methods for MPs}

\subsection{Sampling and pretreatment processes of MPs}

Sampling and pretreatment processes of MPs include the collection of samples from the environment and the extraction of MPs from the samples. Approaches for sampling and extracting MPs from various environmental matrixes, such as freshwater and seawater (Hidalgo-Ruz et al., 2012; Karakolis et al., 2019), sand and sediments (Nuelle et al., 2014; Besley et al., 2017), and organisms and tissues (Claessens et al., 2013; Avio et al., 2015) have been critically reviewed (Hidalgo-Ruz et al., 2012; Mai et al., 2018; Prata et al., 2019a). Therefore, we summarize just the basic steps for the sampling and pretreatment processes of MPs. We emphasize the importance of digestion protocols in fluorescence staining for MPs, which directly influence the staining effect and the accuracy of detection.

\subsubsection{Sample collection processes}

In field studies, different methods and equipment are applied to collect samples in specific environmental matrixes, including water, sand, sediment, the atmosphere, and biota (Table 1) (Dowarah et al., 2020; Scircle et al., 2020; Valine et al., 2020). For water samples, manta nets or trawls are commonly used to collect large-sized MPs $(>100 \mu \mathrm{m})$ in surface waters, whereas pumping with filters $(100$ or $300 \mu \mathrm{m})$ is used as a complemental sampling method for smaller sized MPs $(<100 \mu \mathrm{m})$. For sediment and sand samples, which are generally sampled from shorelines and bottoms of rivers, lakes, or seafloors, the top $0-5 \mathrm{~cm}$ layer of the surface of beaches and sediments is most commonly collected (Patchaiyappan et al., 2020). Sediment cores are also collected to study the occurrence and transport of MPs in aquatic environments. For biota samples, fish, invertebrates, and bivalves are most frequently collected. Biota samples are generally collected from wild environments, but some are sampled from commercial operations (Mai et al., 2018). Processes used to separate the MPs from collected samples include sieving, filtration, and drying, as shown in Table 1. Sieving is generally considered as the first step in sample processing for water and sand or sediment samples, and a mesh of $3 \mathrm{~mm}$ or $5 \mathrm{~mm}$ is used.

\subsubsection{Digestion and density separation processes of MPs}

The widely distributed NOM in the environment can lead to overestimation of the particle number and environment concentration of MPs. Thus, the digestion step is usually followed by sieving to eliminate NOM (Mai et al., 2018). The most commonly applied digestion protocol is adding $\mathrm{H}_{2} \mathrm{O}_{2}(30 \%)$ and $\mathrm{Fe}(\mathrm{II})$ solution to samples (Prata et al., 2019a). Then the mixture was heated at $75^{\circ} \mathrm{C}$ for $0.5-4 \mathrm{~h}$. This digestion method is recommended by US National Oceanic and Atmospheric Administration (NOAA) (Hanke et al., 2013). Moreover, the procedures of digestion depend on the source of environmental samples, which contain different concentrations of NOM. For instance, the digestion for water samples with low content of NOM by $\mathrm{H}_{2} \mathrm{O}_{2}(30 \%)$ is enough, while for sediment or sand samples containing high concentration of NOM requires $\mathrm{H}_{2} \mathrm{O}_{2}$ $(30 \%)$ with $\mathrm{Fe}(\mathrm{II})$ solution $(0.05 \mathrm{M})$ and to be heated at $75^{\circ} \mathrm{C}$ (Fu et al., 2020). When dealing with biota samples, the digestion protocol is extremely important because of the high biomass content, and an enzyme (such as proteinase $\mathrm{K}$, chitinase, and cellulase) is commonly

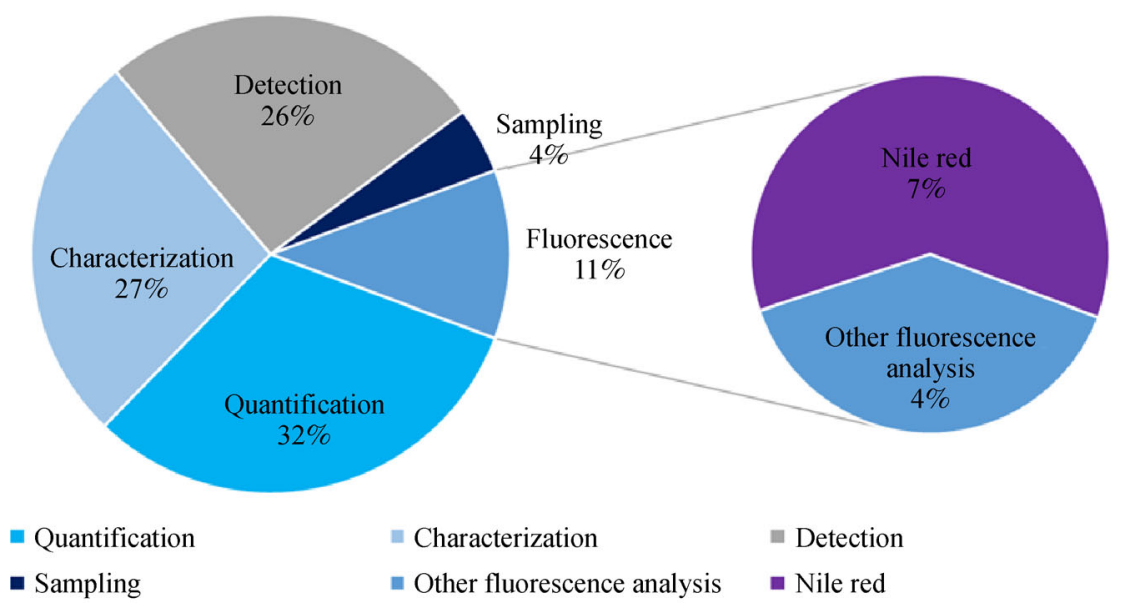

Fig. 1 The proportion of research papers investigating the quantification and characterization of microplastic. 
Table 1 Sampling and pretreatment processes of MPs for fluorescence staining

\begin{tabular}{|c|c|c|c|c|c|c|c|c|c|}
\hline \multirow[b]{2}{*}{ Sample origin } & \multicolumn{3}{|c|}{ Sample collection process } & \multirow[b]{2}{*}{ Sieving } & \multicolumn{3}{|c|}{ Sample pretreatment process } & \multirow[b]{2}{*}{$\begin{array}{c}\text { Extraction } \\
\text { recovery }\end{array}$} & \multirow[b]{2}{*}{ Ref. } \\
\hline & $\begin{array}{c}\text { Sampling } \\
\text { location }\end{array}$ & $\begin{array}{c}\text { Sampling } \\
\text { equipment }\end{array}$ & $\begin{array}{c}\text { Sampling } \\
\text { details }\end{array}$ & & $\begin{array}{c}\text { Density } \\
\text { separation }\end{array}$ & Digestion & Filtration & & \\
\hline Fresh water & $\begin{array}{c}\text { Kinnickinnic } \\
\text { River, USA }\end{array}$ & $\begin{array}{c}\text { Glass jar } \\
1 \mathrm{~L}\end{array}$ & $\mathrm{NA}$ & NA & NA & $\begin{array}{c}0.05 \mathrm{M} \mathrm{FeSO}_{4} \\
\mathrm{H}_{2} \mathrm{SO}_{4} \\
30 \% \mathrm{H}_{2} \mathrm{O}_{2}\end{array}$ & $\begin{array}{c}\text { Polycarbonate } \\
\text { filter } \\
0.4 \mu \mathrm{m}\end{array}$ & $\mathrm{NA}$ & $\begin{array}{c}\text { Simmerman } \\
\text { \& Wasik, } \\
2020\end{array}$ \\
\hline Fresh water & $\begin{array}{l}\text { Four rivers, } \\
\text { USA }\end{array}$ & $\begin{array}{l}\text { Plankton } \\
\text { tow net } \\
200-\mu \mathrm{m}\end{array}$ & $\begin{array}{c}\text { Below } \\
\text { river } \\
\text { surface } \\
0.3-1 \mathrm{~m}\end{array}$ & NA & $\begin{array}{c}84.2 \mathrm{mg} / \mathrm{L} \\
\mathrm{NaCl}\end{array}$ & $10 \% \mathrm{KOH}$ & $\begin{array}{l}\text { Strainer } \\
200 \mu \mathrm{m}\end{array}$ & NA & $\begin{array}{l}\text { Valine } \\
\text { et al., } \\
2020\end{array}$ \\
\hline Sea water & $\begin{array}{l}\text { Mississippi } \\
\text { Sound, USA }\end{array}$ & $\begin{array}{l}\text { Glass jar } \\
946 \mathrm{~mL}\end{array}$ & $\begin{array}{c}\text { Below } \\
\text { surface } \\
\text { water }\end{array}$ & $\begin{array}{l}25-\mu \mathrm{m} \\
\text { mesh }\end{array}$ & NA & $\begin{array}{c}0.05 \mathrm{M} \mathrm{Fe}(\mathrm{II}) \\
30 \% \mathrm{H}_{2} \mathrm{O}_{2}\end{array}$ & $\begin{array}{c}\text { Polycarbonate } \\
\text { filter } \\
10 \mu \mathrm{m}\end{array}$ & NA & $\begin{array}{l}\text { Scircle } \\
\text { et al., } \\
2020\end{array}$ \\
\hline Beach sand & $\begin{array}{c}\text { Three beaches, } \\
\text { India }\end{array}$ & NA & $\begin{array}{c}\text { Top of } \\
\text { beach sand } \\
3-4 \mathrm{~cm}\end{array}$ & $\begin{array}{l}\text { 5-mm } \\
\text { mesh }\end{array}$ & $\begin{array}{c}\mathrm{CaCl}_{2} \\
1.34 \mathrm{~g} / \mathrm{cm}^{3}\end{array}$ & $\mathrm{H}_{2} \mathrm{O}_{2}$ & $\begin{array}{c}\text { Mesh } \\
38 \mu \mathrm{m}\end{array}$ & $\begin{array}{l}89.5 \%- \\
97.5 \%\end{array}$ & $\begin{array}{l}\text { Tiwari } \\
\text { et al., } \\
2019\end{array}$ \\
\hline Sediment & $\begin{array}{c}\text { South } \\
\text { Andaman } \\
\text { beaches, } \\
\text { India }\end{array}$ & $\begin{array}{l}\text { Metal } \\
\text { spoon }\end{array}$ & $\begin{array}{l}\text { Top layer } \\
\text { of beach } \\
1 \mathrm{~cm}\end{array}$ & $\begin{array}{l}3-\mathrm{mm} \\
5-\mathrm{mm} \\
\text { mesh }\end{array}$ & $\begin{array}{c}\mathrm{NaCl} \\
1.2 \mathrm{~g} / \mathrm{cm}^{3}\end{array}$ & $\begin{array}{c}0.05 \mathrm{M} \mathrm{Fe}(\mathrm{II}) \\
30 \% \mathrm{H}_{2} \mathrm{O}_{2}\end{array}$ & $\begin{array}{r}\text { Vacuum } \\
\text { filtration }\end{array}$ & NA & $\begin{array}{c}\text { Patchaiyappan } \\
\text { et al., } 2020\end{array}$ \\
\hline $\begin{array}{l}\text { Biota } \\
\text { (Macroinvertebrates) }\end{array}$ & $\begin{array}{l}\text { Kinnickinnic } \\
\text { River, USA }\end{array}$ & $\begin{array}{l}\text { D-shaped } \\
\text { kick net } \\
600-\mu \mathrm{m}\end{array}$ & NA & NA & NA & $\begin{array}{c}0.05 \mathrm{M} \mathrm{FeSO}_{4} \\
3 \mathrm{~mL} \mathrm{H}_{2} \mathrm{SO}_{4} \\
30 \% \mathrm{H}_{2} \mathrm{O}_{2}\end{array}$ & $\begin{array}{l}\text { Steel sieve } \\
20 \mu \mathrm{m}\end{array}$ & NA & $\begin{array}{l}\text { Simmerman } \\
\text { \& Wasik, } \\
2020\end{array}$ \\
\hline $\begin{array}{l}\text { Biota } \\
\text { (bivalve) }\end{array}$ & $\begin{array}{l}\text { Puducherry } \\
\text { coastline, } \\
\text { India }\end{array}$ & $\begin{array}{l}\text { Bought } \\
\text { in fish } \\
\text { market }\end{array}$ & NA & NA & NA & $10 \% \mathrm{KOH}$ & $\begin{array}{l}\text { Vacuum } \\
\text { filtration } \\
11 \mu \mathrm{m}\end{array}$ & NA & $\begin{array}{l}\text { Dowarah } \\
\text { et al., } 2020\end{array}$ \\
\hline $\begin{array}{l}\text { Biota } \\
\text { (mussels) }\end{array}$ & $\begin{array}{l}\text { Forth } \\
\text { River, } \\
\text { UK }\end{array}$ & $\begin{array}{l}\text { Stainless- } \\
\text { steel } \\
\text { wired } \\
\text { scrubber }\end{array}$ & NA & NA & $\begin{array}{l}\text { Super- } \\
\text { saturated } \\
\mathrm{NaCl}\end{array}$ & $\begin{array}{c}\text { Enzyme } \\
\text { mixture } \\
\text { (Corolase } \\
7089)\end{array}$ & $\begin{array}{l}\text { Vacuum } \\
\text { filtration } \\
0.8 \mu \mathrm{m}\end{array}$ & NA & $\begin{array}{l}\text { Catarino } \\
\text { et al., } 2018\end{array}$ \\
\hline Atmosphere & $\begin{array}{c}\text { Hamburg } \\
\text { metropolitan } \\
\text { area, } \\
\text { Germany }\end{array}$ & $\begin{array}{l}\text { PE-funnel } \\
\text { PE bottle }\end{array}$ & $\begin{array}{c}\text { Above } \\
\text { ground } \\
\text { level } \\
100 \mathrm{~cm}\end{array}$ & NA & NA & $\begin{array}{l}15 \% \mathrm{v} / \mathrm{v} \\
\mathrm{NaClO}\end{array}$ & $\begin{array}{l}\text { Vacuum } \\
\text { filtration } \\
5-13 \mu \mathrm{m}\end{array}$ & NA & $\begin{array}{c}\text { Klein \& } \\
\text { Fischer, } \\
2019\end{array}$ \\
\hline
\end{tabular}

$N A$ means it is not available in the references.

applied to eliminate the tissue (Prata et al., 2019a). In addition, there are other digestion methods, such as acid digestion, alkali digestion, oxidizing digestion, and enzymatic digestion (Prata et al., 2019a). Detailed digestion procedures for each method have been discussed in published reviews (Prata et al., 2019a).

After the digestion step, density-separation procedure is conducted to separate specific MPs from water, soil, or sediment samples. Based on the different densities of plastics $\left(0.8-1.6 \mathrm{~g} / \mathrm{cm}^{3}\right)$ and sediment $\left(2.7 \mathrm{~g} / \mathrm{cm}^{3}\right)$, densityseparation methods have been developed to separate MPs and sediment or sand by mixing the samples in saltsaturated solutions and afterwards collecting the supernatant, which contains MPs (Rocha-Santos and Duarte, 2015). In the density-separation step, the most frequently used salt is $\mathrm{NaCl}$, while other salts such as $\mathrm{CaCl}_{2}, \mathrm{NaI}$, and $\mathrm{ZnBr}_{2}$ are also available (Prata et al., 2019a). Filtration is necessary after the digestion protocol, where all the samples are retained on the filter and the pour size of filter determines the retention particle size. The filters with pour sizes in the range between $0.2 \mu \mathrm{m}$ and $55 \mu \mathrm{m}$ have been used in different studies based on their purpose. The smaller pour size of filter they used, the smaller sized plastic particles can be retained on the filter for further detection. In addition, considering the visual observation of MPs, the filter should not exhibit a fluorescence signal and interfere the detection result. For example, a study tested 6 types of filters and found that only glass fiber filter $(1.2 \mu \mathrm{m})$ and black polycarbonate filters $(0.2 \mu \mathrm{m})$ are appropriate for the detection of NR-stained MPs without introduction of fluorescence intensity from the filters (Prata et al., 2019b). Some plastic particles directly identified by visual observation cannot use the special filter membrane. After filtration, drying procedures (generally at $60^{\circ} \mathrm{C}$ ) are carried out, and they are indispensable as the final steps for sample processing. 


\subsubsection{Quality assurance and quality control in the sampling} process

Guaranteeing quality assurance and quality control (QA/ QC) in the sampling process is essential to get reliable findings concerning the abundance of MPs. For example, procedural blanks (only containing water) and spiked blanks (containing water with known composition and number of MPs) should be analyzed during sample collection and processing of samples (Hanke et al., 2013; Catarino et al., 2018). In addition, the recovery rate of MPs throughout the whole sampling process should be reported to reveal the actual level of MPs in the environment. Determining the recovery rate is also beneficial, because it allows comparison of the abundance with other studies (Wiggin and Holland, 2019). Currently, the recovery rates of generally used sampling processes (sieving, digestion, density separation, and filtering) for MPs can reach 83.3\%-96.6\% (Maes et al., 2017; Tamminga, 2017). In field sampling, non-plastic collection tools and storage containers should be used to avoid cross contamination. During laboratory sampling, it is necessary to wear latex gloves and cotton clothes to avoid contamination from airborne fibers, which are widely detected in the environment via atmospheric fallout (Ziajahromi et al., 2017). Overall, quality assurance and quality control protocols are
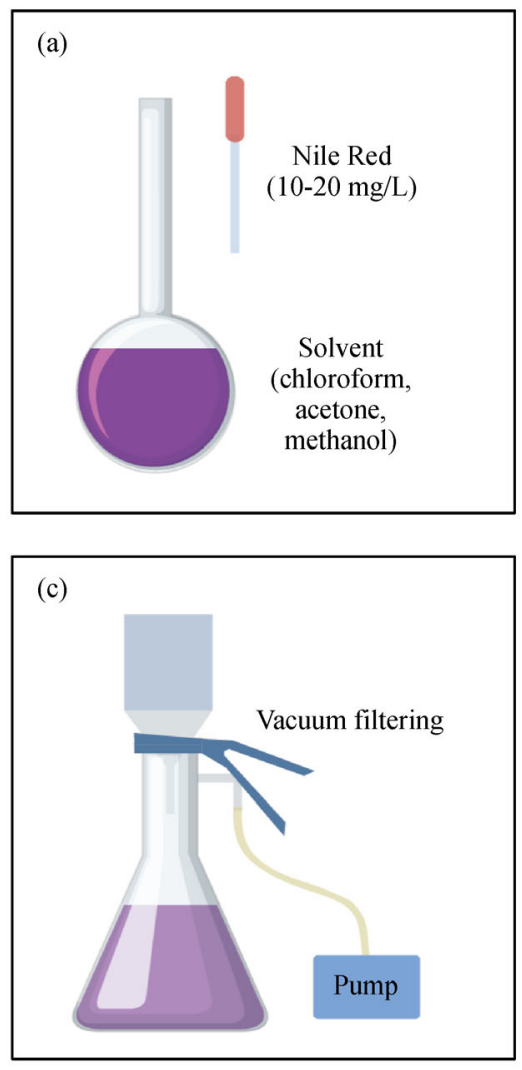

important to get accurate and reliable data and high recovery rates during the entire sampling processes.

\subsection{Methods for fluorescence staining of MPs}

Fluorescence methods are distinguished from regular, optical approaches to detect and quantify MPs, because they require a staining process during pretreatment. The fluorescence staining methods for MPs can be categorized into staining MPs on filter paper or in solution. The first dying method for MPs on filter paper includes collecting the environmental samples, separating and extracting the MPs from the environmental samples, placing the MPs on filter paper (usually a polycarbonate filter paper), and adding the dye solution on the filter paper to stain the MPs for a period of time (2-4 h) (Shim et al., 2016; ErniCassola et al., 2017). After the staining procedure, the number or concentrations of the stained MPs are detected by a fluorescence microscope or spectrophotometer.

The other method is staining MPs in solution (Cook et al., 2020; Karakolis et al., 2019), as shown in Fig. 2. The first step is preparation of the staining solution (Fig. 2a), which is an organic solvent that dissolves the NR. The most commonly used solvents include methanol, chloroform, acetone, and $n$-hexane (Tamminga, 2017). The second step is suspending MPs in the staining solution

(b)

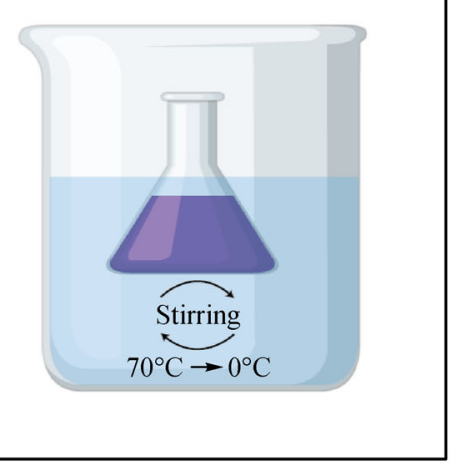

(d)

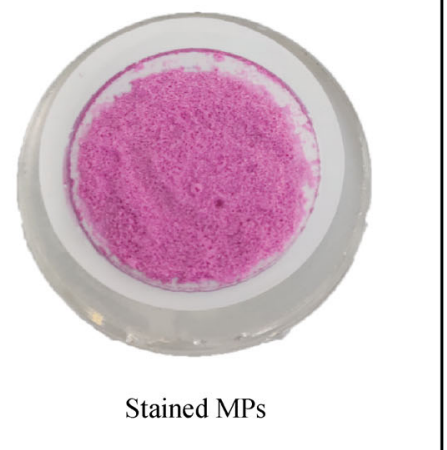

Fig. 2 MP staining process in solution. (a) adding Nile Red in solvent, (b) staining in solution while heating and cooling, (c) vacuum filtering, (d) Nile Red stained MPs. 
(Fig. 2b). The heating and cooling procedures may enhance the intensity of the fluorescence signal and inhibit leaching of the dye (Lv et al., 2019). The third step is filtering the staining solution to get the fluorescencestained MPs and washing them with deionized water to get rid of the adsorbed dye (Fig. 2c). Then, the fluorescencestained MPs are obtained, and they usually show red or purple color when NR is used as dye (Fig. 2d).

In early studies, the staining method on filter paper was commonly applied and was used for most types of polymers (Shim et al., 2016; Erni-Cassola et al., 2017). In recent years, staining in solution is an improved method due to stirring and the addition of heating or cooling procedures. Therefore, recent studies tend to stain MPs in solution (Stanton et al., 2019; Konde et al., 2020). This staining method requires MPs to be distributed in a homogeneous solution. Thus, it may be difficult to use with certain types of MPs such as PE, which tends to float on the surface of water due to its low density. To solve this problem, researchers have suspended a powder of PE in a mixture of ultrapure water and dimethyl sulfoxide $(v=1: 1)$ for better distribution in solution (Cook et al., 2020). In conclusion, to get a better staining effect, the staining method for MPs in solution is recommended, which has the advantages of flexible heating or stirring procedures.

\subsection{Factors influencing the staining effect}

The staining effect of MPs depends on many factors, such as dye concentration, solvent type, and temperature (Wiggin and Holland, 2019). In this section, we comprehensively discuss how these factors influence the staining effect to develop an optimum MP staining protocol.

\subsubsection{Physicochemical properties of MPs}

The physicochemical properties of MPs, such as particle size, shape, and composition, affect the staining process (Wiggin and Holland, 2019). The recovery rate of fluorescent-stained MPs decreases as the size of particle decreases. For example, studies have found that recovery rates of NR-stained MPs decreased from $82 \%$ to $49 \%$ when the size decreased from 500 to $1000 \mu \mathrm{m}$ to $20-63$ $\mu \mathrm{m}$, respectively (Wiggin and Holland, 2019), which may be because the smaller particles are more difficult to be detected under a microscope. Moreover, approximately $95 \%$ of particles with sizes larger than $1 \mathrm{~mm}$ could be detected after staining by NR, while only $71.7 \%$ of particles smaller than $1 \mathrm{~mm}$ could be detected (Tamminga, 2017), which was primarily because the small particles were stained less strongly and exhibited a weaker fluorescence intensity; therefore, they were more difficult to be detected than larger particles.

In addition, the shapes of the MPs can influence the staining effect, which are generally categorized as particles, fragments, or fibers. Studies have indicated that fibers are especially difficult to be stained compared with particles and fragments due to their irregular shapes (Tamminga, 2017). Moreover, the color of MPs may disturb the staining effect and quantification. Most commonly used plastics are white, which plays a minor role in detection after staining. But certain polymer types, like PVC in black color, are difficult to be stained and detected (Shim et al., 2016).

The composition of MPs determines the affinity between MPs and dyes. As a hydrophobic dye, NR preferentially combines with polymer materials such as PP and PE that have a low polarity. Fluorescence staining using lipophilic dyes, such as NR, has proven to be effective in quantification of small particles of PE, PP, PS, PC, PUR, and PEVA, because of their high hydrophobicity, whereas PVC, PA, and PES could not be detected after staining due to their low hydrophobicity (Shim et al., 2016). Among the physicochemical properties of MPs, the chemical composition of the polymer plays a primary role in the staining effect, and it determines the affinity between MPs and dyes. To note, the fluorescence staining has minor effect on the aggregation of MPs. On the one hand, Raman spectrum and FTIR spectra measurements prove that the stained MPs have almost no alteration on composition compared to pristine MPs, because only a few dye molecules are added into MPs surface by diffusion (Lv et al., 2019). On the other hand, the Zeta potentials of pristine PET MPs and NR stained PET MPs have been measured, their Zeta potentials are $-6.00 \pm 0.78 \mathrm{mV}$ and $-7.64 \pm 0.81 \mathrm{mV}$, respectively. This proves that staining process has a minor effect on the surface charge of MPs. Similarly, the Zeta potentials of stained PE, PP, and PVC MPs were also measured and no significant alteration of Zeta potentials has been observed.

\subsubsection{Experimental parameters}

\section{1) NR concentration}

Fluorescence intensity of stained MPs is influenced by the concentration of NR, which has been applied in the range of $0.1 \mu \mathrm{g} / \mathrm{mL}$ and $500 \mu \mathrm{g} / \mathrm{mL}$ in current studies (Rumin et al., 2015; Lv et al., 2019). For example, Lv et al. found that fluorescence intensity first increased $(0.1-25 \mu \mathrm{g} / \mathrm{mL}$ NR concentration) and then decreased (25-100 $\mu \mathrm{g} / \mathrm{mL}$ NR concentration) with NR concentration (Lv et al., 2019), which was attributed to NR aggregation at high dye concentration that decreased fluorescence intensity (Rumin et al., 2015). Similarly, the fluorescence intensity increased and then decreased with rising dye concentration $(0.1-$ $100 \mu \mathrm{g} / \mathrm{mL}$ ) when selecting Fluorescein isophosphate (FITC) to stain MPs. The fluorescence intensity increased with Safranine $\mathrm{T}$ dye concentration increasing from $0.1 \mu \mathrm{g} / \mathrm{mL}$ to $100 \mu \mathrm{g} / \mathrm{mL}$, while it changed slightly until the dye concentration reached saturation at $100 \mu \mathrm{g} / \mathrm{mL}(\mathrm{Lv}$ et al., 2019). Moreover, a high NR concentration, such as 
$500 \mu \mathrm{g} / \mathrm{mL}$, may lead to saturation of spectrometer intensity. An obvious red shift in fluorescence spectra of PVC could interfere with the fluorescence measurement and analysis (Konde et al., 2020). Thus, attention should be paid to avoid using too high a NR concentration for staining. Conversely, low NR concentration $(<1 \mu \mathrm{g} / \mathrm{mL})$ exhibits too weak fluorescence signals to detect (Konde et al., 2020). Therefore, an appropriate NR concentration between $10 \mu \mathrm{g} / \mathrm{mL}$ and $20 \mu \mathrm{g} / \mathrm{mL}$ is suggested in NR staining protocols, which gets both adequate fluorescence intensity and minimum interference (Tamminga, 2017).

\section{2) Solvent}

NR is a hydrophobic dye with poor solubility and weak fluorescence in water (Greenspan and Fowler, 1985). It first needs to be dissolved in a solvent for staining. The solvent has a significant impact on the NR staining effect. On the one hand, the solvent directly affects the recovery rate of the fluorescent-stained MPs. On the other hand, NR contains a polar carboxyl function $(-\mathrm{COOH})$ on its aromatic rings; therefore, NR fluorescence spectra exhibit dependency on the polarity of solvents due to the solvatochromism of NR (Rumin et al., 2015). Because of the relatively polar nature of NR molecules when compared to plastics, the partitioning of NR molecules from the solvent to plastics can be made more feasible in non-polar solvents, such as $n$-hexane, than in polar solvents (Shim et al., 2016).

The use of various solvents, such as chloroform, acetone, $n$-hexane, and methanol, has been summarized in the literature (Tamminga, 2017; Konde et al., 2020). Tamminga et al. investigated the influence of three solvents, which were acetone, chloroform, and $n$-hexane, on the staining effect of MPs by NR. Chloroform was the most appropriate solvent for HDPE, LDPE, PP, and PVC, and the lowest recovery rate was $83.3 \%$ (Tamminga, 2017). Nevertheless, they found that some polymer materials, such as cellulose acetone and PS, had the tendency to dissolve in chloroform or acetone (Tamminga, 2017). Konde et al. proposed a mixed solvent consisting of acetone and ethanol with $v / v=1: 1$ for the investigation of MP photoluminescence spectra, and the mixed solvent exhibited strong fluorescence intensity without PVC deformation (Konde et al., 2020). Overall, it is necessary to select an appropriate solvent to avoid leaching of the additive or monomer from MPs; to develop specific fluorescence spectra for each solvent; and to get reliable detection results of fluorescence-stained MPs. A mixture of solvents, like acetone and ethanol, appears to offer a good choice for staining.

\section{3) Temperature}

Temperature has a significant impact on the staining effect, because the adsorption of the dye onto the NP or MP surface, or the entrance of dye inside polymer molecules, depends on temperature. Fluorescence is exhibited only for a short period when MPs are stained at room temperature $\left(25^{\circ} \mathrm{C}\right)$ without heating (Prata et al., 2020). For example, after 2 months, $73.5 \%$ of NR-stained MPs without heating were found to have lost fluorescence (Prata et al., 2020), which was attributed to the desorption of dye molecules from the MP surface because the dyes were just adsorbed onto the surface. Studies have found that the heating protocol promotes the staining effect resulting in both higher fluorescence intensity and a more stable florescence signal for a long period (over 2 months) (Lv et al., 2019). Fluorescence intensity of MPs has shown an increasing trend with increasing temperatures from $20^{\circ} \mathrm{C}$ to $50^{\circ} \mathrm{C}$ (Konde et al., 2020). Most types of MPs have their strongest fluorescence intensity at $50^{\circ} \mathrm{C}$, except for PVC which has its strongest fluorescence at $75^{\circ} \mathrm{C}$ ( $\mathrm{Lv}$ et al., 2019). Furthermore, heating protocols have enabled stained MPs to maintain a stable fluorescence intensity over 2 months (Lv et al., 2019). Heating protocols have been applied in several studies and to obtain high recovery rates (> 95\%) (Cook et al., 2020; Karakolis et al., 2019; Lv et al., 2019). The heating temperature of staining solutions in previous studies have generally been set from $50^{\circ} \mathrm{C}$ to $75^{\circ} \mathrm{C}$ (Cook et al., 2020; Karakolis et al., 2019; Lv et al., 2019; Konde et al., 2020). The temperature should be lower than the melting point of some polymer materials such as LDPE $\left(85^{\circ} \mathrm{C}\right)$. PVC and PET are less hydrophobic plastics and, thus, are difficult to be stained by NR. The use of a heating protocol enables PVC and PET to exhibit strong fluorescence intensity (Lv et al., 2019). Overall, to obtain stronger fluorescence intensity and a more stable staining effect for MPs, the protocol of heating staining solutions is recommended. When the melting point of polymer materials is considered, $50^{\circ} \mathrm{C}-60^{\circ} \mathrm{C}$ would be an appropriate temperature range to use for NR staining protocols.

\subsection{Advantages of fluorescence staining for MPs}

Fluorescence staining for quantification of MPs provides a straightforward, quick, cheap, and convenient technique to detect mass concentration of MPs and to investigate their distribution in environmental samples. Spectral methods or chromatographic methods can cost up to hundreds of dollars for each batch of samples, while the cost of NR is only $\$ 8.36 \mathrm{USD} / \mathrm{g}$ plastic with the additional need for fluorescence microscopy (Karakolis et al., 2019).

Fluorescence-staining methods also have been represented as a time efficient and convenient way for quantification of MPs. The staining protocol of MPs could be as short as $30 \mathrm{~min}$ for one batch of samples, while spectral methods take a longer time for detection of MPs. For example, FTIR requires at least nine hours to scan one filter paper (Shim et al., 2017) including the requirement of sample pretreatment time. The work experience required 
for quantification of MPs via fluorescence techniques is much less than that needed for spectral (i.e. FTIR) or mass spectrometry methods (Rocha-Santos and Duarte, 2015). Quantification of MPs via fluorescence can be operated by automated photo-analysis software. In contrast, the mass spectrometry method, like GC-MS, requires well-trained operators as well as time-consuming pretreatment processes (Rocha-Santos and Duarte, 2015). Overall, the major advantages of fluorescence-staining methods are that they are time efficient and easy to use, and they are appropriate for the detection of the abundance of MPs in bulk environmental samples.

In addition, NR staining protocols improve the count efficiencies of smaller-sized MPs compared with those taken with regular visual quantification methods. A study showed that NR staining increased the detection number of MPs in every sample, and the greatest increase of the numbers observed was in the smaller sized fraction $(<124$ $\mu \mathrm{m})$ (Wiggin and Holland, 2019). Furthermore, this study showed that the reported levels of MPs determined via the NR staining and counting approach were higher than those determined by other methods worldwide, and this was likely due to the inclusion of smaller sized MPs after dyeing samples from a highly urbanized aquatic environment (Los Angeles, California) (Wiggin and Holland, 2019). Overall, smaller-sized MPs are more likely to be detected by the NR staining method, and it avoids underestimation of MP abundance in the environment. However, there are challenges for detecting the small-sized MPs, and the detection limit by the current fluorescence staining method for the size of MPs was down to $3 \mu \mathrm{m}$ (Wiggin and Holland, 2019). Meanwhile, the detection limit of MPs mass concentration by fluorescence staining methods lies in the range between $1 \mathrm{mg} / \mathrm{L}$ and $100 \mathrm{mg} / \mathrm{L}$ (Li et al., 2019).

\section{Fluorescence identification and quantifi- cation methods for MPs}

\subsection{Identification}

Basically, identifying MPs with fluorescence microscopes includes the following steps: 1) the samples are placed under the fluorescence microscope and are excited with the proper excitation wavelength; 2) the samples are observed or photographed under the proper emission wavelength; 3 ) the fluorescence signal or images are detected and analyzed for identification. In detail, the particles were identified as MPs by the following criteria: 1) no cellular or organic structure are observed; 2) fiber particles are uniform in thickness throughout their whole length and have no three-dimensional bending; 3) the colored particles should present clear and homogeneous colors; 4) fiber particles have no segment; 5) particles do not shine (Nor and Obbard, 2014; Klein and Fischer, 2019).
After confirming the fluorescent particles as MPs, these particles are counted either by manual work or automated software (such as ImageJ) to obtain the number of particles. To be specific, the total number of low abundance of MPs can be counted directly on the entire filter. While counting the high abundance of MP samples, it is commonly to count the total particles from 3 random fields of view and averaging these counts, then comparing the viewed area with the entire filter area and normalizing the observed numbers to the whole filter area (Simmerman and Wasik, 2020).

The influence of the excitation wavelength on the detection of stained MPs has been explored. Prata et al. tested NR-stained mixtures of polymers (PE, PP, PS, PVC, EPS, nylon) and organic matter and excited them under light with multiple wavelengths $(254,365,470,495,530$, $625 \mathrm{~nm}$ ) (Prata et al., 2020). The results showed that excitation light at $254 \mathrm{~nm}$ had the advantage of a high contrast with the background signals without interference with organic matter. But PS, PVC, nylon, virgin HDPE, and weathered PE could hardly be detected under the $254 \mathrm{~nm}$ excitation wavelength. Most polymers (PE, PP, HDPE, PS, EPS) and NOM could be excited under $470 \mathrm{~nm}$ at the same time. Therefore, application of the $470 \mathrm{~nm}$ excitation wavelength requires a digestion step to remove NOM (Prata et al., 2019b). In conclusion, the $254 \mathrm{~nm}$ excitation wavelength is suitable for limited types of polymers (PE, PP) with the advantage of less interference by NOM. The excitation wavelength at $470 \mathrm{~nm}$ can excite most types of polymers but it can excite NOM as well, which requires digestion procedures to avoid interference with the NOM's fluorescence signal.

During the identification procedures, the fluorescence signals from MPs have different colors (Fu et al., 2020). The NR-stained plastics appear orange color in a chloroform solvent when excited by blue or UV light (Maes et al., 2017; Tamminga, 2017). In addition, MPs can fluoresce in varied light ranges when stained by different dyes. For example, iDye pink (pink dye), iDye blue (blue dye), and Rit DyeMore Kentucky Sky (Kentucky dye) can fluoresce in the red range, the far red range, and the green and red (both) ranges, respectively (Karakolis et al., 2019).

With the help of image-analysis techniques, the hydrophobic and hydrophilic characteristics of fluorescence particles can be identified. Using this method, a simple "fluorescence index" can be calculated as $(R+G) / R$ ('R' and ' $G$ ' are the 8-bit color intensity values of red and green, respectively). This index represents the "polarity" of the polymer surface, and the larger the value of the index is, the higher hydrophobicity of the polymer particles is (Maes et al., 2017; Tamminga, 2017; Wiggin and Holland, 2019). Recently, an automated counting software (MPVAT, Microplastics Visual Analysis Toll) has been developed, which can be applied to detect the sizes and shapes of stained MPs through their emitted light (Prata et al., 2019b). 


\subsection{Quantification}

The identification of MPs is commonly followed by a quantification procedure. Identification can provide information about the morphology and surface properties of MPs, while quantification can show the number and mass concentrations of MPs in samples, in order to study abundance and occurrence of MPs (Mai et al., 2018). Procedures for quantification with fluorescence microscopes involve the following steps: 1 ) the MPs are excited under an excitation wavelength; 2) their fluorescence signal is observed; and 3) the fluorescence particles are counted or selected MPs are picked up for further mass weighing and quantifying (Prata et al., 2020).

In addition, using a fluorescence spectrophotometer to determine the mass concentration of MPs in a water matrix is also feasible, based on a standard curve that is developed to show the relationship between fluorescence intensity and MP concentration (Li et al., 2019). An example for quantification of stained PET using a fluorescence spectrophotometer is shown in Fig. 3. This method is especially appropriate for simulated samples done under laboratory conditions, which consist of pure polymers and little NOM (Shim et al., 2016). For example, a study was done with fluorescence polystyrene nanoplastics (PSNPs, $100 \mathrm{~nm}$ ) and polyethylene MPs (PEMPs, $1.0-1.2 \mathrm{~mm}$ ) to investigate their aggregation and settling mechanisms in sandy water. In this study, a fluorescence spectrophotometer was used to measure the fluorescence intensity of MPs, and then the MP mass concentration was further calculated using a standard curve (Li et al., 2019). In conclusion, fluorescence MPs provide a fast method for quantification of MP concentration, and the particles can easily be detected using their fluorescence intensity.

The quantification methods used for field samples and laboratory samples are different. In one study, field samples were first photographed under a certain excitation wavelength (Klein and Fischer, 2019). Then, images were analyzed by software to count the number of fluorescence plastic particles. The size and particle circularity could also be determined by image-analysis software (Sfriso et al., 2020). As for laboratory samples, they can be detected easily and accurately by using a fluorescence spectrophotometer, because they have a known polymer type and few impurities (Li et al., 2019). Recently, fully- or semiautomated analytical methods have been applied to quantify MPs, which offer a promising way of MP quantification in the future. Confocal microscopy also has provided a straightforward way to observe stained MPs. A study demonstrated that artificially generated MPs are more recognizable under confocal microscopy than field samples (Maxwell et al., 2020). Therefore, confocal
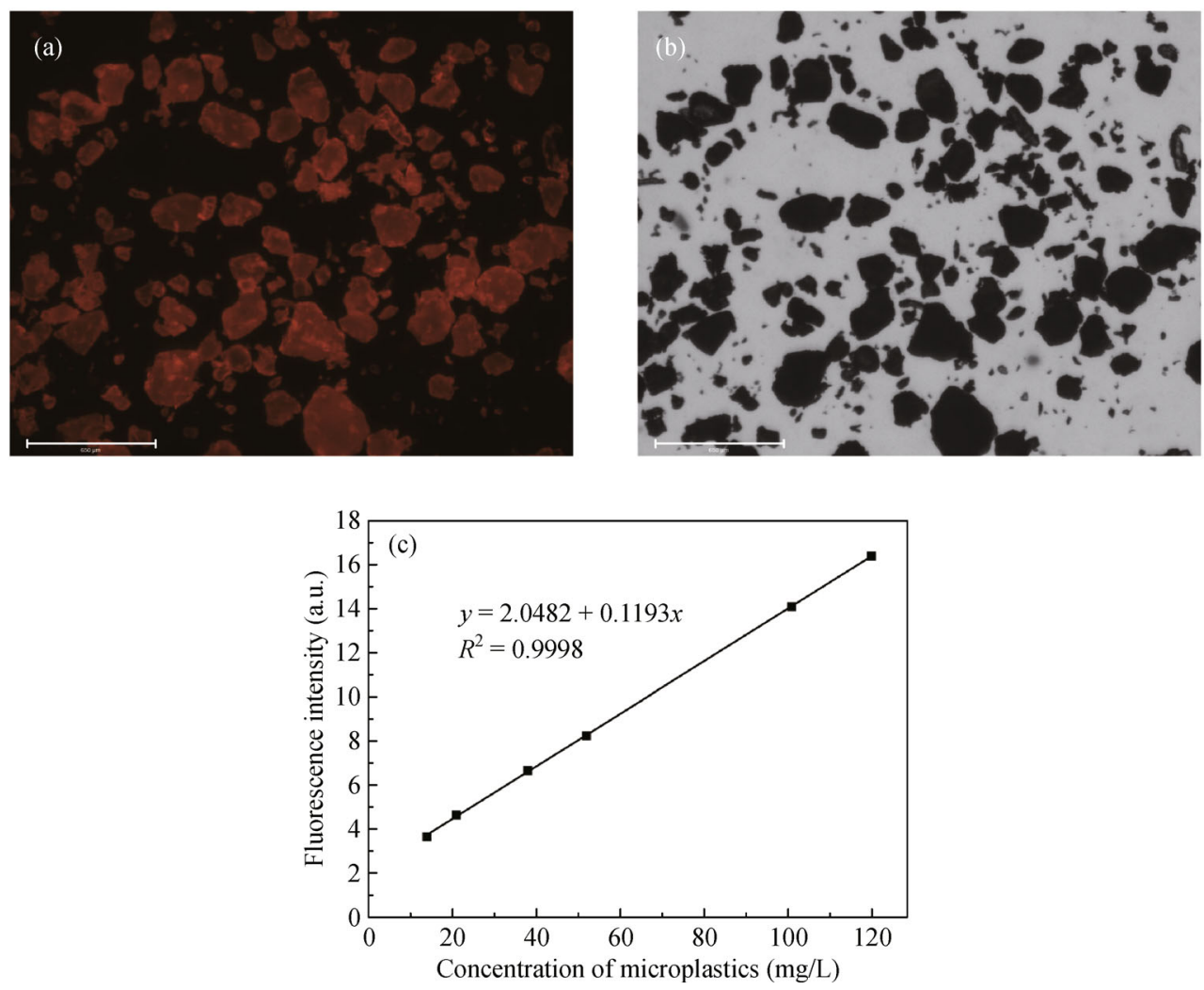

Fig. 3 Quantification of MPs using fluorescence spectrophotometer (a) fluorescence stained PET microplastic when being excited, (b) fluorescence stained PET microplastic under bright-field, Scale bar $=650 \mu \mathrm{m}$, (c) correlation curve between fluorescence intensity and mass concentration of PET microplastic. 
microscopy could be more appropriate in laboratory studies (Maxwell et al., 2020). The use of Laser Confocal Raman Spectroscopy in identifying and quantifying MPs can increase the sensitivity and accuracy of analysis. This advanced technology can identify the physical properties and chemical compositions of MPs, with the advantages of high spectral coverage, high lateral resolution, specific fingerprint spectrum and low interference from organic matter/water/fluorescence background signals (Sobhani et al., 2019). Thus, Laser Confocal Raman Spectroscopy has a promising future especially in the study of transport and transformation of nanostructured materials in natural waters.

\section{Application of information from studies of fluorescence-stained MPs}

\subsection{Quantification of MPs input in the environment}

Microplastics can enter the terrestrial, aquatic, and atmospheric environments directly through indiscriminate disposal of plastic wastes and indirectly through application of waste resources containing plastics such as biosolids and composts (Bradney et al., 2019; Kumar et al., 2020). The fluorescence-quantification method of MPs has been developed in recent years, and it has been validated to be a straightforward and cost-effective way to quantify the input of MPs into environments through various waste sources (Lares et al., 2019). For example, Lares et al. compared six different methods to detect MPs in municipal wastewater and digested sludge samples, spiked with seven different types of plastic particles and fiber, and they suggested that a staining method using Rose Bengal could be useful in separating MPs from other materials (Lares et al., 2019). Another study examined the occurrence of MPs in wild mussels via fluorescence staining using NR. The results showed that the mean concentration of MPs entering the body of Modiolus (a kind of mussel) was $0.086 \pm 0.031$ items $/ g$ wet weight (Catarino et al., 2018). The authors also reported that the ingestion of airborne fibers by humans during a meal can be up to $13731-68415$ items/y/person. In these studies, the staining method was applied to separate MPs from other materials and to quantify the input of MPs into the environment.

\subsection{Measurement of MPs abundance in the environment}

The fluorescence-quantification method has been applied to measure the concentrations of MPs in samples of fresh water, seawater, soil, beach sand, sediment, airborne MPs, and biota (Vermaire et al., 2017; Gagné et al., 2019; Klein and Fischer, 2019; Simmerman and Wasik, 2020). In two studies in India, the abundance of MPs in beach sand was determined by NR-staining MPs. In one study, concentra- tions of MPs were 45-220 items $/ \mathrm{kg}$ of dry sand (South Andaman beach) and in the other study they were 161.7973.3 items/kg of dry sand (Girgaon Mumbai, Tuticorin beach, Dhanushkodi beach) (Tiwari et al., 2019; Patchaiyappan et al., 2020). Simmerman et al. examined the MP levels in water and organisms in a cold-water stream in western Wisconsin, USA. They found that the concentrations of MPs stained by NR in water ranged from 545 to 3622 items/L and increased significantly from upstream to downstream. The mean MP concentrations downstream of an urban area were 2-3 times those found upstream (Simmerman and Wasik, 2020), which may be because MPs move down stream with the water flow. Klein et al. examined the MP abundance in atmospheric disposition via fluorescence MP quantification. They determined that the mean MP abundance was 275 items $/ \mathrm{m}^{2} / \mathrm{d}$. To characterize the chemical composition of MPs, Raman spectroscopy was combined with fluorescence quantification, and polyethylene/ethylvinyl acetate copolymers were found to dominate within the metropolitan area of Hamburg, Germany (Klein and Fischer, 2019). In conclusion, dye stained MPs and the fluorescence quantification approach have been applied in field samples to examine the abundance of MPs, which are generally coupled with spectroscopic methods to characterize the composition of MPs (Vermaire et al., 2017; Klein and Fischer, 2019; Patchaiyappan et al., 2020).

\subsection{Investigation of distribution of MPs in organisms}

Assessment of the toxicity of MPs in organisms requires characterization of their distribution in organisms. Fluorescence detection methods have been widely applied in distribution studies of MPs, which may facilitate toxicity assessments of marine organisms and evaluation of human health risks (Catarino et al., 2018; Maxwell et al., 2020). Maxwell et al. reported a novel counterstaining method by NR, Evans blue, and Calcofluor white dyes to detect MPs in terrestrial, invertebrate samples. The results could be used for investigation of MP ingestion by soil animals (Maxwell et al., 2020). They studied the tissue distribution of PS-MPs in red tilapia (O. niloticus) during a 14-d exposure period. They found that the concentration of PSMPs in the fish gut was $171.1 \times 10^{4} \pm 3.5 \times 10^{4} \mu \mathrm{g} / \mathrm{kg}$, and the concentration of microplastics in organs were in the order of gut $>$ gills $>$ livers $\approx$ brain (shown in Fig. 4) (Ding et al., 2018). Overall, fluorescence staining of MPs can be used to study the distribution and accumulation of MPs in tissues of organisms, and the results can be helpful for the assessment of the toxicity of MPs to evaluate human health risk.

4.4 Investigation of the environmental fate and transport of MPs

Fluorescence staining and quantification methods have 

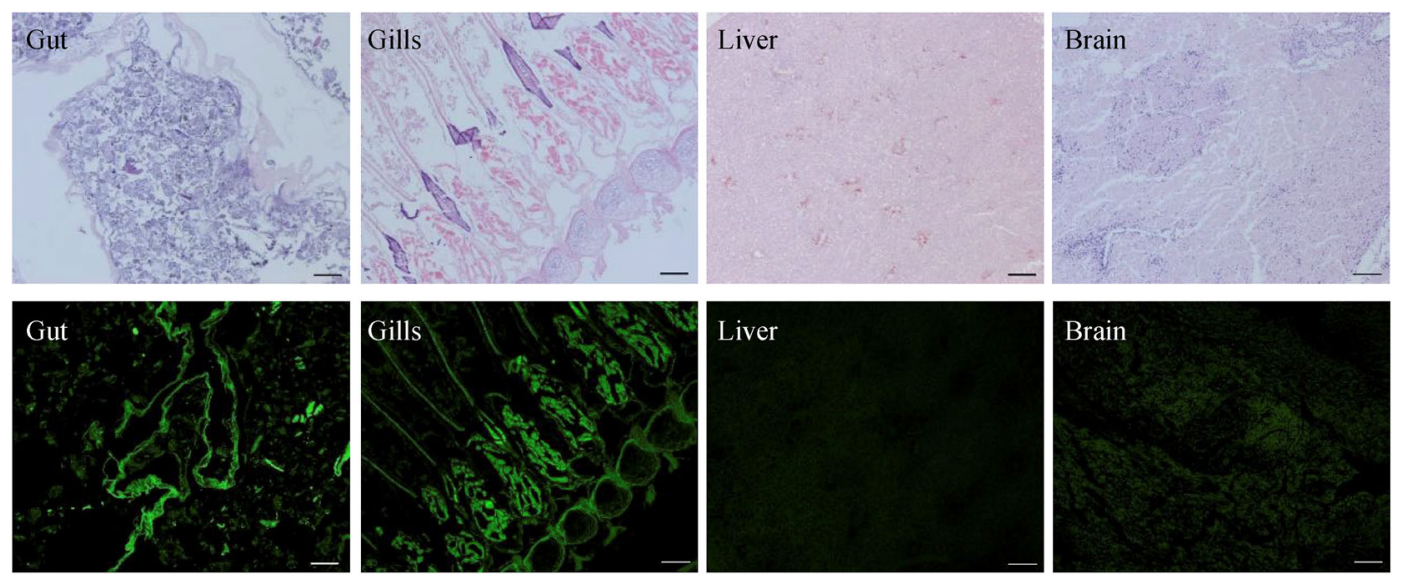

Fig. 4 Photographs of fish tissues under a bright-field microscope (top row) and representative fluorescence images of PS-MPs in different fish tissues after $14 \mathrm{~d}$ of the exposure to $100 \mu \mathrm{g} / \mathrm{L}$ (bottom row), Scale bar $=100 \mu \mathrm{m}$. Graph was adapted from ref (Ding et al., 2018) with permission.

been applied to determine the environmental fate of MPs. Results from simulated, laboratory experiments are extremely useful. In simulated experiments done under laboratory conditions, $\mathrm{Li}$ et al. studied the aggregation behavior of MPs in suspended sediment (SS) using fluorescence PSNPs and PEMPs to quantify the concentration of MPs (Li et al., 2019). They found that PSNPs and SS formed heteroaggregates and settled in a water column at a settling velocity of $0.010 \mathrm{~m} / \mathrm{s}$, which can affect the distribution and fate of PSNPs in aquatic environments. In contrast, the settling velocity for heteroaggregates of PEMPs and SS was low $\left(\sim 10^{-5} \mathrm{~m} / \mathrm{s}\right)$, which indicated that the effect of SS on the settling and distribution of PEMPs is negligible. In addition, Cook et al. used NRstained PEMPs to measure their longitudinal dispersion coefficients in laboratory flumes (Cook et al., 2020). They calculated that the longitudinal dispersion coefficients ranged from 0.0030 to $0.0690 \mathrm{~m}^{2} / \mathrm{s}$ for PE particles. Their results were used to establish a model concerning the transport of MPs in natural rivers. In summary, fluorescence staining and quantification methods facilitate a comprehensive understanding of the fate and transport of MPs in aquatic and terrestrial environments.

\section{Conclusions and future prospects}

The novel fluorescence staining and quantification method is straightforward, quick, cheap, and reliable for quantification of MP abundance and MP distribution in the environment, including water, soil, sediments, and organisms (Duan et al., 2021; Liu et al., 2021; Wang et al., 2021). The method is especially suitable for detection of MPs in large, bulk environmental samples and laboratory samples. However, challenges regarding detection of MPs and quantification of their concentrations remain, as described in the following sections.
5.1 Strengthen research on the synthesis of novel dye to avoid interference of organic matter

Organic matter is ubiquitous in natural aquatic, terrestrial, or biotic environments. Dyes can co-stain it along with plastic particles, which interferes with the detection of MP fluorescence intensity and results in overestimation of the abundance of plastic particles in samples, and, consequently, their accumulation and toxicity is overstated (Stanton et al., 2019). Therefore, pre-purification of samples is required to remove organic matter. In a study with benthic invertebrate samples, it was found that the use of the NR staining method should take digestion protocols into consideration, because chitin cannot be removed by $\mathrm{H}_{2} \mathrm{O}_{2}$ digestion. It can get stained by NR and exhibits a strong fluorescence intensity leading to false positives (Sfriso et al., 2020). Thus, future studies should be done to develop counterstaining methods with novel dyes to distinguish the fluorescence intensity of MPs from that of organic matter in order to avoid interfere in the quantification of plastic particles.

5.2 Combine fluorescence staining with other chemical methods to analyze MPs composition

The fluorescence-staining technique facilitates the quantification of the number, concentration, or abundance of MPs in various environmental matrixes. However, the fluorescence-staining method cannot stain all types of polymers, because of the different affinity between dyes and plastics (Stanton et al., 2019). For example, NR can stain plastics like PP, PE, PS, PC, EPS, PU, and PEVA but cannot stain plastics like PVC, PA, and PES (Shim et al., 2016). In addition, the NR-staining method does not provide information about the chemical bonds of the detected MPs, and the method may be combined with spectroscopic techniques to determine the chemical 
composition of plastic particles (Erni-Cassola et al., 2017). To better elucidate the transport, availability, and toxicity of MPs, combinational analysis, in which fluorescence staining is used with chemical identification methods like FTIR and IR, is a current trend in studies concerning the occurrence and abundance of MPs.

5.3 Develop image-analysis methods for quantification of stained MPs

Developing fully- or semi-automated image-analysis protocols when using the fluorescence staining and quantification method has a broad future. Currently, manual counting of the numbers of MPs under fluorescent or optical microscopy is the most applied of the methods used for the quantification of the abundance and concentration of MPs. It has a low efficiency and may cause error. Therefore, automated image analysis would be helpful and provide researchers with both accuracy and efficiency to save time and labor. The challenge for the future of image-analysis methods includes the counting of complex aggregates, which are widely distributed in aquatic and terrestrial environments.

\subsection{Improve the stability of stained MPs}

The migration, transport, and transformation of MPs in natural aquatic, terrestrial, or biotic systems is a long-term process. The affinity between MPs and dyes may be affected by different environmental conditions, such as $\mathrm{pH}$, dissolved oxygen concentrations, ionic strength, or temperature. The altered interaction between MPs and dyes, as a function of chemical conditions of the water, may result in leaching of the dye from stained plastic particles, causing a decrease in fluorescence intensity and stability of the stained MPs. Further studies are needed to assess the factors that influence fluorescence stability, in order to optimize the staining process and support longterm research concerning the occurrence, transformation, and toxicity of MPs.

\subsection{Develop detection method for nanoplastics}

Nanoplastics $(<100 \mathrm{~nm})$ might cause more adverse environmental problems, due to their smaller size and higher specific surface area (Sobhani et al., 2020). Standardized methods for nanoplastics identification are required to understand their risks in the environment, which is currently still a challenge. X-ray photoelectron spectroscopy, FTIR, and Raman spectroscopy have been used to study the surface texture and structural information of nanoplastics (Sobhani et al., 2020). However, their small sizes usually generate a weak signal for analysis, resulting in false positive or false negative detection. Tip-enhanced Raman scattering (TERS), scanning near-field optical microscopy (SNOM), and superlens have also been developed to provide the mapping image of the sample and high lateral resolution of optical images (Sobhani et al., 2019). However, how to improve the resolution of measurement when detecting nanoplastics and overcoming nano- scale effects are huge challenges. Future work is suggested to develop detection methods of nanoplastics to improve superior analytical algorithms and enhance the weak signal from nanoplastics.

Acknowledgements This study was supported by the National Key R\&D Program of China (Grant No. 2017YFA0605001), the National Natural Science Foundation of China (Grant Nos. 52170024, 21677015 and 22006031), the Natural Science Foundation of Hebei Province (No. B2019204315), and the Sponsored Research Overhead Fund (Grant No. 472120) from Kansas State University.

Open Access This article is licensed under a Creative Commons Attribution 4.0 International License, which permits use, sharing, adaptation, distribution and reproduction in any medium or format, as long as you give appropriate credit to the original author(s) and the source, provide a link to the Creative Commons licence, and indicate if changes were made. The images or other third party material in this article are included in the article's Creative Commons licence, unless indicated otherwise in a credit line to the material. If material is not included in the article's Creative Commons licence and your intended use is not permitted by statutory regulation or exceeds the permitted use, you will need to obtain permission directly from the copyright holder. To view a copy of this licence, visit http://creativecommons.org/licenses/by/4.0/.

\section{References}

Alimi O S, Farner Budarz J, Hernandez L M, Tufenkji N (2018). Microplastics and nanoplastics in aquatic environments: Aggregation, deposition, and enhanced contaminant transport. Environmental Science \& Technology, 52(4): 1704-1724

Avio C G, Gorbi S, Regoli F (2015). Experimental development of a new protocol for extraction and characterization of microplastics in fish tissues: First observations in commercial species from Adriatic Sea. Marine Environmental Research, 111: 18-26

Barnes D K A, Galgani F, Thompson R C, Barlaz M (2009). Accumulation and fragmentation of plastic debris in global environments. Philosophical Transactions of the Royal Society of London. Series B, Biological Sciences, 364(1526): 1985-1998

Besley A, Vijver M G, Behrens P, Bosker T (2017). A standardized method for sampling and extraction methods for quantifying microplastics in beach sand. Marine Pollution Bulletin, 114(1): 7783

Bradney L, Wijesekara H, Palansooriya K N, Obadamudalige N, Bolan N S, Ok Y S, Rinklebe J, Kim K H, Kirkham M B (2019). Particulate plastics as a vector for toxic trace-element uptake by aquatic and terrestrial organisms and human health risk. Environment International, 131: 104937

Browne M A, Crump P, Niven S J, Teuten E, Tonkin A, Galloway T, Thompson R (2011). Accumulation of microplastic on shorelines woldwide: Sources and sinks. Environmental Science \& Technology, 45(21): 9175-9179

Carbery M, O'Connor W, Palanisami T (2018). Trophic transfer of microplastics and mixed contaminants in the marine food web and implications for human health. Environment International, 115: 400- 
409

Catarino A I, Macchia V, Sanderson W G, Thompson R C, Henry T B (2018). Low levels of microplastics (MP) in wild mussels indicate that MP ingestion by humans is minimal compared to exposure via household fibres fallout during a meal. Environmental Pollution, 237: 675-684

Chen Y, Leng Y, Liu X, Wang J (2020). Microplastic pollution in vegetable farmlands of suburb Wuhan, Central China. Environmental Pollution, 257: 113449

Claessens M, Van Cauwenberghe L, Vandegehuchte M B, Janssen C R (2013). New techniques for the detection of microplastics in sediments and field collected organisms. Marine Pollution Bulletin, 70(1-2): 227-233

Cole M, Lindeque P, Halsband C, Galloway T S (2011). Microplastics as contaminants in the marine environment: A review. Marine Pollution Bulletin, 62(12): 2588-2597

Cook S, Chan H L, Abolfathi S, Bending G D, Schäfer H, Pearson J M (2020). Longitudinal dispersion of microplastics in aquatic flows using fluorometric techniques. Water Research, 170: 115337

Ding J, Zhang S, Razanajatovo R M, Zou H, Zhu W (2018). Accumulation, tissue distribution, and biochemical effects of polystyrene microplastics in the freshwater fish red tilapia (Oreochromis niloticus). Environmental Pollution, 238: 1-9

Dowarah K, Patchaiyappan A, Thirunavukkarasu C, Jayakumar S, Devipriya S P (2020). Quantification of microplastics using Nile Red in two bivalve species Perna viridis and Meretrix meretrix from three estuaries in Pondicherry, India and microplastic uptake by local communities through bivalve diet. Marine Pollution Bulletin, 153: 110982

Duan J, Bolan N, Li Y, Ding S, Atugoda T, Vithanage M, Sarkar B, Tsang D C W, Kirkham M B (2021). Weathering of microplastics and interaction with other coexisting constituents in terrestrial and aquatic environments. Water Research, 196: 117011

Erni-Cassola G, Gibson M I, Thompson R C, Christie-Oleza J A (2017). Lost, but found with Nile Red: A novel method for detecting and quantifying small microplastics $(1 \mathrm{~mm}$ to $20 \mu \mathrm{m})$ in environmental samples. Environmental Science \& Technology, 51(23): 1364113648

Fu W, Min J, Jiang W, Li Y, Zhang W (2020). Separation, characterization and identification of microplastics and nanoplastics in the environment. Science of the Total Environment, 721: 137561

Gagné F, Auclair J, Quinn B (2019). Detection of polystyrene nanoplastics in biological samples based on the solvatochromic properties of Nile red: Application in Hydra attenuata exposed to nanoplastics. Environmental Science and Pollution Research International, 26(32): 33524-33531

Greenspan P, Fowler S D (1985). Spectrofluorometric studies of the lipid probe, nile red. Journal of Lipid Research, 26(7): 781-789

Guo B, Meng J, Wang X, Yin C, Hao W, Ma B, Tao Z (2020). Quantification of pesticide residues on plastic mulching films in typical farmlands of the North China. Frontiers of Environmental Science \& Engineering, 14(1): 2

Hanke G, Galgani F, Werner S, Oosterbaan L, Nilsson P, Fleet D, Kinsey S, Thompson R, Van Franeker J A, Vlachogianni T (2013). Guidance on monitoring of marine litter in European seas. Luxembourg. doi, 10: 99475
Hidalgo-Ruz V, Gutow L, Thompson R C, Thiel M (2012). Microplastics in the marine environment: A review of the methods used for identification and quantification. Environmental Science \& Technology, 46(6): 3060-3075

Jee A Y, Park S, Kwon H, Lee M (2009). Excited state dynamics of Nile Red in polymers. Chemical Physics Letters, 477(1-3): 112-115

Karakolis E G, Nguyen B, You J B, Rochman C M, Sinton D (2019). Fluorescent dyes for visualizing microplastic particles and fibers in laboratory-based studies. Environmental Science \& Technology Letters, 6(6): 334-340

Klein M, Fischer E K (2019). Microplastic abundance in atmospheric deposition within the Metropolitan area of Hamburg, Germany. Science of the Total Environment, 685: 96-103

Konde S, Ornik J, Prume J A, Taiber J, Koch M (2020). Exploring the potential of photoluminescence spectroscopy in combination with Nile Red staining for microplastic detection. Marine Pollution Bulletin, 159: 111475

Kumar M, Xiong X, He M, Tsang D C W, Gupta J, Khan E, Harrad S, Hou D, Ok Y S, Bolan N S (2020). Microplastics as pollutants in agricultural soils. Environmental Pollution, 265(Pt A): 114980

Lares M, Ncibi M C, Sillanpää M, Sillanpää M (2019). Intercomparison study on commonly used methods to determine microplastics in wastewater and sludge samples. Environmental Science and Pollution Research International, 26(12): 12109-12122

Li Y, Wang X, Fu W, Xia X, Liu C, Min J, Zhang W, Crittenden J C (2019). Interactions between nano/micro plastics and suspended sediment in water: Implications on aggregation and settling. Water Research, 161: 486-495

Liu X, Wang J (2020). Algae (Raphidocelis subcapitata) mitigate combined toxicity of microplastic and lead on Ceriodaphnia dubia. Frontiers of Environmental Science \& Engineering, 14(6): 97

Liu Y, Shao H, Liu J, Cao R, Shang E, Liu S, Li Y (2021). Transport and transformation of microplastics and nanoplastics in the soil environment: A critical review. Soil Use and Management, 37(2): 224-242

Lv L, Qu J, Yu Z, Chen D, Zhou C, Hong P, Sun S, Li C (2019). A simple method for detecting and quantifying microplastics utilizing fluorescent dyes: Safranine T, fluorescein isophosphate, Nile Red based on thermal expansion and contraction property. Environmental Pollution, 255(Pt 2): 113283

Maes T, Jessop R, Wellner N, Haupt K, Mayes A G (2017). A rapidscreening approach to detect and quantify microplastics based on fluorescent tagging with Nile Red. Scientific Reports, 7: 44501

Mai L, Bao L J, Shi L, Wong C S, Zeng E Y (2018). A review of methods for measuring microplastics in aquatic environments. Environmental Science and Pollution Research International, 25(12): 11319-11332

Maxwell S H, Melinda K F, Matthew G (2020). Counterstaining to separate Nile Red-stained microplastic particles from terrestrial invertebrate biomass. Environmental Science \& Technology, 54(9): $5580-5588$

McCormick A, Hoellein T J, Mason S A, Schluep J, Kelly J J (2014). Microplastic is an abundant and distinct microbial habitat in an urban river. Environmental Science \& Technology, 48(20): 11863-11871

Nor N H, Obbard J P (2014). Microplastics in Singapore's coastal mangrove ecosystems. Marine Pollution Bulletin, 79(1-2): 278-283

Nuelle M T, Dekiff J H, Remy D, Fries E (2014). A new analytical 
approach for monitoring microplastics in marine sediments. Environmental Pollution, 184: 161-169

Patchaiyappan A, Ahmed S Z, Dowarah K, Jayakumar S, Devipriya S P (2020). Occurrence, distribution and composition of microplastics in the sediments of South Andaman beaches. Marine Pollution Bulletin, 156: 111227

Prata J C, Alves J R, da Costa J P, Duarte A C, Rocha-Santos T (2020). Major factors influencing the quantification of Nile Red stained microplastics and improved automatic quantification (MP-VAT 2.0). Science of the Total Environment, 719: 137498

Prata J C, Da Costa J P, Duarte A C, Rocha-Santos T (2019a). Methods for sampling and detection of microplastics in water and sediment: A critical review. Trends in Analytical Chemistry, 110: 150-159

Prata J C, Reis V, Matos J T V, da Costa J P, Duarte A C, Rocha-Santos $\mathrm{T}$ (2019b). A new approach for routine quantification of microplastics using Nile Red and automated software (MP-VAT). Science of the Total Environment, 690: 1277-1283

Rocha-Santos T, Duarte A C (2015). A critical overview of the analytical approaches to the occurrence, the fate and the behavior of microplastics in the environment. Trends in Analytical Chemistry, 65: 47-53

Rumin J, Bonnefond H, Saint-Jean B, Rouxel C, Sciandra A, Bernard O, Cadoret J P, Bougaran G (2015). The use of fluorescent Nile red and BODIPY for lipid measurement in microalgae. Biotechnology for Biofuels, 8: 42

Scircle A, Cizdziel J V, Tisinger L, Anumol T, Robey D (2020). Occurrence of microplastic pollution at Oyster Reefs and other coastal sites in the Mississippi Sound, USA: Impacts of freshwater inflows from flooding. Toxics, 8(2): 35

Sfriso A A, Tomio Y, Rosso B, Gambaro A, Sfriso A, Corami F, Rastelli E, Corinaldesi C, Mistri M, Munari C (2020). Microplastic accumulation in benthic invertebrates in Terra Nova Bay (Ross Sea, Antarctica). Environment International, 137: 105587

Shahul Hamid F, Bhatti M S, Anuar N, Anuar N, Mohan P, Periathamby A (2018). Worldwide distribution and abundance of microplastic: How dire is the situation? Waste Management and Research, 36(10): 873-897

Shim W J, Hong S H, Eo S E (2017). Identification methods in microplastic analysis: A review. Analytical Methods, 9(9): 13841391

Shim W J, Song Y K, Hong S H, Jang M (2016). Identification and quantification of microplastics using Nile Red staining. Marine Pollution Bulletin, 113(1-2): 469-476

Simmerman C B, Wasik J K C (2020). The effect of urban point source contamination on microplastic levels in water and organisms in a cold-water stream. Limnology and Oceanography Letters, 5(1): $137-$ 146

Sobhani Z, Al Amin M, Naidu R, Megharaj M, Fang C (2019). Identification and visualisation of microplastics by Raman mapping. Analytica Chimica Acta, 1077: 191-199

Sobhani Z, Zhang X, Gibson C, Naidu R, Megharaj M, Fang C (2020). Identification and visualisation of microplastics/nanoplastics by
Raman imaging (i): Down to $100 \mathrm{~nm}$. Water Research, 174: 115658 Stanton T, Johnson M, Nathanail P, Gomes R L, Needham T, Burson A (2019). Exploring the efficacy of Nile Red in microplastic quantification: A costaining approach. Environmental Science \& Technology Letters, 6(10): 606-611

Sun L, Sun N, Bai L, An X, Liu B, Sun C, Fan L, Wei C, Han Y, Yu M, Lin J, Lu D, Wang N, Xie L, Shen K, Zhang X, Xu Y, CabanillasGonzaleze J, Huang W (2019). Alkyl-chain branched effect on the aggregation and photophysical behavior of polydiarylfluorenes toward stable deep-blue electroluminescence and efficient amplified spontaneous emission. Chinese Chemical Letters, 30(11): 1959-1964

Tamminga M (2017). Nile Red staining as a subsidiary method for microplastic quantification: A comparison of three solvents and factors influencing application reliability. SDRP Journal of Earth Sciences \& Environmental Studies, 2(2): 165-168

Thompson R C, Olsen Y, Mitchell R P, Davis A, Rowland S J, John A W G, McGonigle D, Russell A E (2004). Lost at sea: where is all the plastic? Science, 304(5672): 838

Tiwari M, Rathod T D, Ajmal P Y, Bhangare R C, Sahu S K (2019). Distribution and characterization of microplastics in beach sand from three different Indian coastal environments. Marine Pollution Bulletin, 140: 262-273

Valine A E, Peterson A E, Horn D A, Scully-Engelmeyer K M, Granek E F (2020). Microplastic prevalence in 4 Oregon rivers along a rural to urban gradient applying a cost-effective validation technique. Environmental Toxicology and Chemistry, 39(8): 1590-1598

Vermaire J C, Pomeroy C, Herczegh S M, Haggart O, Murphy M, Schindler D E (2017). Microplastic abundance and distribution in the open water and sediment of the Ottawa River, Canada, and its tributaries. Facets, 2(1): 301-314

Wang X, Bolan N, Tsang D C W, Sarkar B, Bradney L, Li Y (2021). A review of microplastics aggregation in aquatic environment: Influence factors, analytical methods, and environmental implications. Journal of Hazardous Materials, 402: 123496

Wiggin K J, Holland E B (2019). Validation and application of cost and time effective methods for the detection of $3-500 \mu \mathrm{m}$ sized microplastics in the urban marine and estuarine environments surrounding Long Beach, California. Marine Pollution Bulletin, 143: $152-162$

Wu W M, Yang J, Criddle C S (2017). Microplastics pollution and reduction strategies. Frontiers of Environmental Science \& Engineering, 11(1): 4

Zhang G S, Liu Y F (2018). The distribution of microplastics in soil aggregate fractions in southwestern China. Science of the Total Environment, 642: 12-20

Zhang S, Liu X, Hao X, Wang J, Zhang Y (2020). Distribution of lowdensity microplastics in the mollisol farmlands of northeast China. Science of the Total Environment, 708: 135091

Ziajahromi S, Neale P A, Rintoul L, Leusch F D (2017). Wastewater treatment plants as a pathway for microplastics: Development of a new approach to sample wastewater-based microplastics. Water Research, 112: 93-99 